\title{
MOleCUlAR EPIDEMIOLOGY OF AfRICAN tRYPANOSOMIASIS: THE CONTRIBUTIONS OF DAVID GEORGE GODFREY OBE TO THE BIOCHEMICAL CHARACTERIZATION OF TRYPANOSOMES
}

\author{
GIBSON W.*,1
}

\section{Summary:}

The accurate identification of the causative organisms of disease is fundamental to the study of epidemiology. Hence molecular tools are now widely used to detect and distinguish pathogens, and have greatly improved our understanding of epidemiology. David Godfrey pioneered the use of molecular markers in the epidemiology of African trypanosomiasis, thus enabling the light of reliable evidence to shine on this previously problematic and controversial subject area. From the early 1970's David's group employed first isoenzyme electrophoresis and subsequently DNAbased characterization methods to aid identification of trypanosomes collected from a range of endemic countries across Africa. These investigations had a major impact on our understanding of the zoonotic nature of human trypanosomiasis in Africa and of the genetic diversity of African trypanosomes.

KEY WORDS : African trypanosomiasis, Trypanosoma brucei, Trypanosoma congolense, Trypanosoma vivax, isoenzyme electrophoresis, reservoir hosts, numerical taxonomy, clonality.

$\tau$ t has always been a major source of confusion that trypanosomes with very different biological characteristics look just the same under the microscope. For example, in the epidemiology of African sleeping sickness, only Trypanosoma brucei gambiense Dutton, 1902 and T. b. rhodesiense Stephens \& Fantham, 1910 can infect humans, but each causes a distinct type of disease and responds differently to particular drugs used for treatment. It is therefore advisable to know which parasite is present in a patient with sleeping sickness before starting chemotherapy.

These two human pathogens T. b. gambiense and T. $b$. rbodesiense, are transmitted to humans and other mammalian hosts by bloodsucking tsetse flies, but the flies and mammals may also carry $T$. b. brucei Plimmer \& Bradford, 1899, a morphologically indistinguishable, nonhuman infective subspecies. It is impossible to distinguish the three subspecies by microscopy and therefore to know with certainty whether any particular trypanosome is human infective or not. This has been a major obstacle to the incrimination of reservoir hosts

* School of Biological Sciences, University of Bristol, Bristol BS8 1UG, UK

Tel.: 44 (0)1 179288249 - E-mail: w.gibson@bris.ac.uk

${ }^{1}$ This paper is dedicated to my PhD supervisor and mentor, David Godfrey, 1929-2007. or vectors of the human pathogens for many years and thus hindered our understanding of the epidemiology of sleeping sickness. David Godfrey was one of the pioneers to address this challenging problem using intrinsic biochemical markers to identify the different kinds of trypanosome (Godfrey, 1978). He firmly believed that an understanding of the epidemiology of African trypanosomiasis is best acquired firsthand through fieldwork in endemic areas, and, during a career spanning 1956 to 1994, he and members of his team worked in The Gambia, Liberia, Ivory Coast, Nigeria, Cameroon, Sudan, Uganda, Kenya, Tanzania and Zambia amassing a huge and representative collection of trypanosome isolates on which to base their analyses and conclusions.

David Godfrey started his research career on trypanosomes in Africa as a parasitologist at the West African Institute for Trypanosomiasis Research at Vom in Northern Nigeria (Fig. 1). Together with Bob Killick-Kendrick, he carried out many fundamental studies on the epidemiology of animal trypanosomiasis, notably following the cattle herds trekked from the tsetse-free regions of northern Nigeria to the slaughter houses of the south to find out where they picked up trypanosome infection (Godfrey et al., 1965). Careful parasitological examination of sequential blood samples

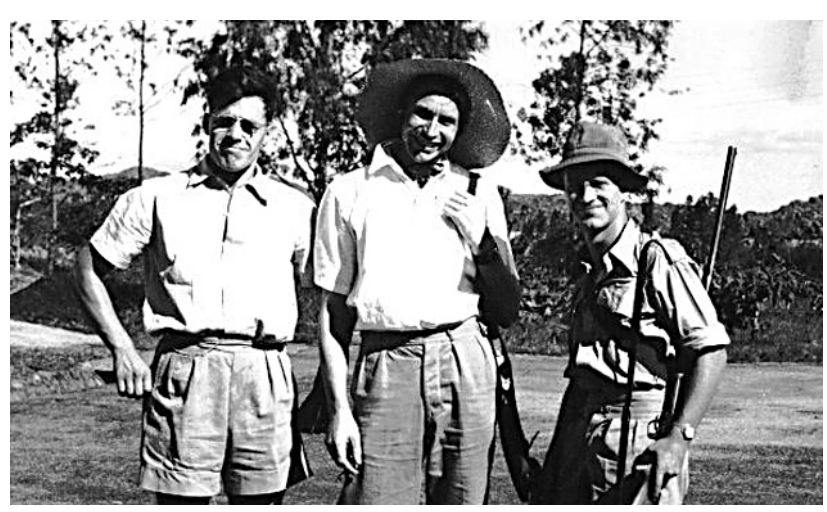

Fig. 1. - Fieldwork in Nigeria, 1957. David Godfrey (left), Kenneth Broomfield (centre) and Bob Killick-Kendrick (right) in 1957 at the West African Institute for Trypanosomiasis Research, Vom, Northern Nigeria. Photograph kindly supplied by David's daughter, Susan Hunt. 
showed that most of these trek cattle picked up trypanosome infection once they encountered tsetse and many acquired infection with more than one trypanosome species. T. brucei sspp. parasitaemias were often very low and only detectable by inoculation of blood into experimental rodents (Godfrey \& KillickKendrick, 1961).

On return to the UK a few years after Nigerian independence in 1960, David became a member of the External Scientific Staff of the Medical Research Council and was based first at the Lister Institute for Preventative Medicine and subsequently at the London School of Hygiene and Tropical Medicine. During this period, Sheila Lanham and he developed the methodology for separating trypanosomes from blood cells using anion exchange chromatography on DEAE cellulose to yield pure trypanosome preparations, a fundamental technique which underpinned many subsequent biochemical studies of bloodstream form trypanosomes (Lanham \& Godfrey, 1970). This single paper has been cited well over 1000 times.

The availability of purified extracts of trypanosome proteins enabled the group to begin work using the then novel technique of isoenzyme electrophoresis to look for genetic polymorphisms in different trypanosome strains. The technique had been widely used for the study of human genetics and was first applied to trypanosome characterization by David's group in collaboration with Charlie Parr at the London Hospital (Bagster \& Parr, 1973; Kilgour \& Godfrey, 1973). The spectacular potential of the technique was soon harnessed to address previously intractable questions such as the identification of T. b. gambiense, the causative organism of sleeping sickness in West Africa. This trypanosome was found to have particular aminotransferase polymorphisms that distinguished it from $T$. $b$. rhodesiense and T. b. brucei (Godfrey \& Kilgour, 1976; Kilgour \& Godfrey, 1973).

Armed with a new tool to identify T. $b$. gambiense, the hunt was on for animal reservoir hosts of this trypanosome. While it had long been accepted that T. b. rhodesiense circulated in zoonotic transmission cycles in East Africa involving both wild and domestic animals, humans were regarded as the sole reservoir of sleeping sickness in West and Central Africa. However, to those with experience of trypanosomiasis in the field, it seemed likely that certain domestic animals such as pigs, commonly found in villages in endemic areas, might harbour T. b. gambiense. A productive partnership between David's group and Dieter Mehlitz and colleagues of the Bernhard Nocht Institute, Hamburg, proved that human sleeping sickness in West Africa has zoonotic as well as anthroponotic transmission cycles (Fig. 2). By isoenzyme electrophoresis, trypanosome isolates from domestic pigs were shown to be identical to isolates from patients with sleeping sickness in

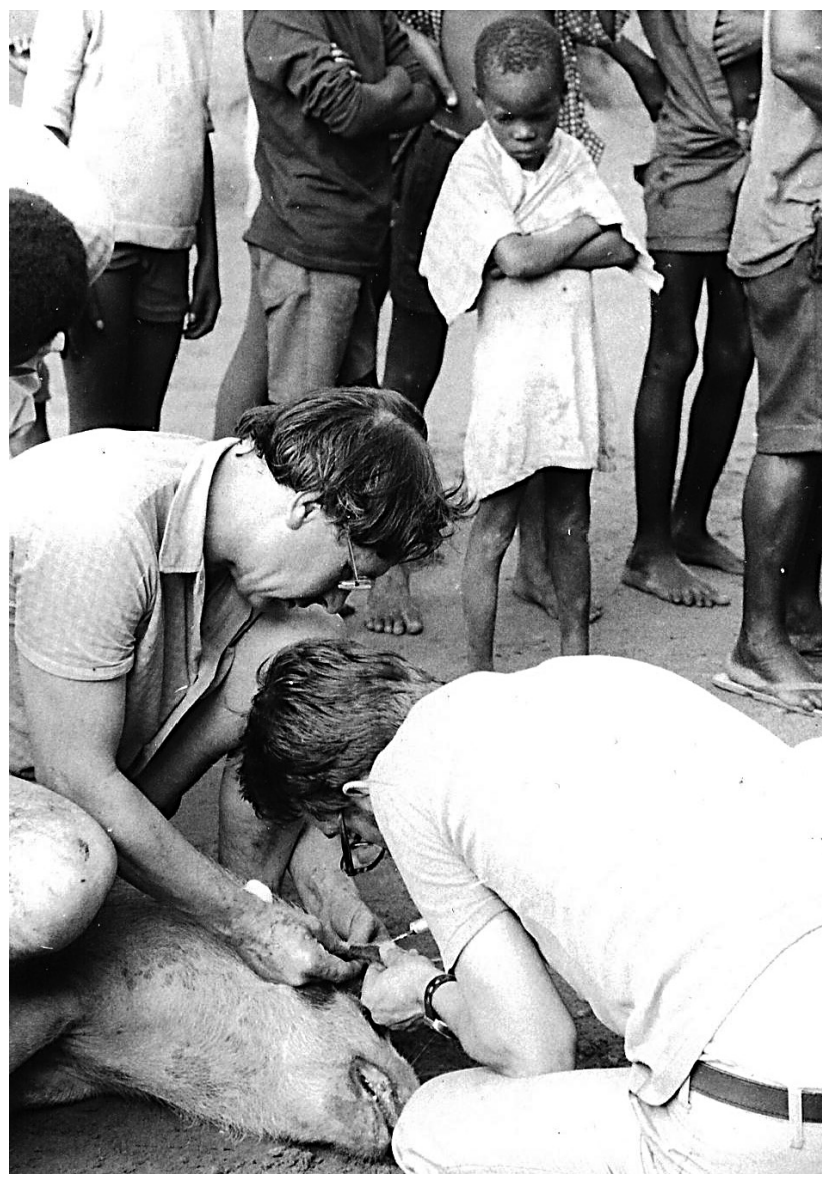

Fig. 2. - Fieldwork in Liberia, 1977. David Godfrey (left) and Uwe Zillman (right) taking blood from a free-ranging pig in Lakayta in Liberia watched by a crowd of villagers.

Ivory Coast, and identical trypanosomes were also found in cattle, kob and hartebeest from Upper Volta (Burkina Faso) (Mehlitz et al., 1982). Some of these trypanosomes had the characteristic aminotransferase polymorphisms of $T . b$. gambiense associated with the chronic form of sleeping sickness in West Africa (Godfrey \& Kilgour, 1976; Kilgour \& Godfrey, 1973), but this study also revealed a new type of $T$. $b$. gambiense in patients and animals, indistinguishable from T. b. brucei and $T . b$. rhodesiense by aminotransferase isoenzyme patterns and characterized by variable sensitivity to the lytic effect of human serum (Mehlitz et al., 1982). Clearly the epidemiology of human sleeping sickness in West Africa was far more complex than previously thought, involving both strain variation and animal reservoir hosts as in East Africa. These results marked a real triumph of biochemical markers to transform our understanding of trypanosomiasis epidemiology.

Although identification of $T . b$. gambiense had thus advanced impressively, results for the other subspecies were less clearcut. T. $b$. rhodesiense had no equivalent distinguishing isoenzyme markers such as the aminotransferase patterns associated with the chronic type 
of $T . b$. gambiense, and isolates of T. b. rhodesiense from geographically separate foci had different combinations of isoenzyme polymorphisms (Gibson et al., 1980). T. b. brucei strains were very polymorphic indeed by isoenzyme electrophoresis (Gibson et al., 1980; Gibson et al., 1978; Mehlitz et al., 1982). The only discernable pattern was a broad division between T. brucei sspp. strains from East and West Africa, which were characterized by different polymorphisms for two isoenzymes, phosphoglucomutase and isocitrate dehydrogenase (Gibson et al., 1980).

To make sense of these results, David sought help from mathematicians, statisticians and computer scientists and forged interdisciplinary collaborations with Tom F. de C. Marshall at LSHTM and Rose Baker at the University of Salford, resulting in two major publications on numerical taxonomy of trypanosomes of the T. brucei group (Gibson et al., 1980; Godfrey et al., 1990). David also recruited young mathematically-minded biologists into his team such as Richard Cibulskis and Jamie Stevens, and encouraged both to study trypanosomiasis firsthand in the field to inform their analytical work back in UK. Their work greatly advanced our understanding of the population genetics of African trypanosomes and sought answers to the controversial question of clonality in T. brucei (Cibulskis, 1988, 1992; Stevens \& Cibulskis, 1990; Stevens \& Godfrey, 1992; Stevens et al., 1992; Stevens et al., 1994; Stevens \& Welburn, 1993).

Biological variation in Trypanosoma congolense Broden, 1904, an important pathogenic tsetse-transmitted trypanosome of livestock in tropical Africa, was one of David's major interests during his early days of trypanosome research in Nigeria (Godfrey, 1960, 1961). Isoenzyme electrophoresis provided the tools to explore strain variation on the fundamental genetic level and the first wide-ranging study quickly revealed the existence of two previously unrecognised groups of T. congolense (Young \& Godfrey, 1983), associated with savannah and riverine-forest biomes in West Africa. It was evident from this study that there was greater genetic diversity within T. congolense than T. brucei, a finding confirmed by analysis of new isolates from the field (Gashumba et al., 1988). Variation in this group of animal trypanosomes belonging to subgenus Nannomonas Hoare, 1964 had been overlooked, despite their importance as animal pathogens. Trypanosomes of subgenus Nannomonas have a characteristic developmental cycle in tsetse, with multiplication in the midgut and proboscis of the tsetse fly. Analysis of midgut trypanosomes collected from tsetse caught in The Gambia culminated in the identification of a completely new trypanosome species, which was named T. godfreyi in David's honour (McNamara et al., 1994).

The investigation of biological variation in another major cattle pathogen, T. vivax Ziemann, 1905 required per- iods of intensive work in Nigeria together with Bello Na'isa of the government Tsetse and Trypanosomiasis Division co-ordinated through a network of collaborators in various veterinary institutes throughout the northern states of the country. Most T. vivax isolates will not grow in laboratory rodents, so the difficulty of collecting sufficient trypanosomes for isoenzyme analysis was overcome by searching for naturally infected cattle with high parasitaemias and preparing trypanosome samples directly from infected blood (Kilgour \& Godfrey, 1977; Kilgour et al., 1975). This is one of the very few studies of natural variation in this parasite and present day researchers can be very grateful that far less material is required for the ubiquitous polymerase chain reaction than isoenzyme electrophoresis.

Before the advent of DNA-based methods for genetic strain typing, isoenzyme electrophoresis was the preeminent tool for exploring strain variation and David inspired work on a range of other parasites besides the African trypanosomes, including T. cruzi Chagas, 1909 (Bogliolo \& Godfrey, 1987; Miles et al., 1977), various vertebrate trypanosomes (Baker et al., 1978; Letch, 1979), Leishmania Ross, 1903 (Leblancq et al., 1986), Entamoeba Casagrandi \& Barbagallo, 1895 (Sargeaunt \& Williams, 1978) and Onchocerca Diesing, 1841 (Flockhart et al., 1986). These publications are but a small indication of David's impact on the field, as, although David and members of his research group were often instrumental in these studies, he is seldom a co-author on any of the resultant publications. This reflects David's great modesty concerning his influence and achievements and his willingness to let junior researchers take the whole credit, myself included. It is indeed salutary to compare this generous and unselfish approach with the world of science today.

\section{ACKNOWLEDGEMENTS}

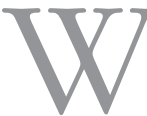

ith thanks to Sue Hunt, Kim Godfrey and Bob Killick-Kendrick for biographical information about David and to Sue Hunt for providing photographs. I am most grateful to Bob Killick-Kendrick for constructive comments on the manuscript.

\section{REFERENCES}

Bagster I.A. \& PARR C.W. Trypanosome identification by electrophoresis of soluble enzymes. Nature, 1973, 244, 364366.

Baker J.R., Miles M.A., Godfrey D.G. \& Barrett T.V. Biochemical characterization of some species of Trypanosoma (Schizotrypanum) from bats (Microchiroptera). American Journal of Tropical Medicine and Hygiene, 1978, 27, 483491. 
Bogliolo A.R. \& Godfrey D.G. Isoenzyme changes during the life-cycle of Trypanosoma cruzi. Transactions of the Royal Society of Tropical Medicine and Hygiene, 1987, 81, 222229.

CiBUlskis R.E. Origins and organization of genetic diversity in natural populations of Trypanosoma brucei. Parasitology, 1988, 96, 303-322.

CiBulskis R.E. Genetic variation in Trypanosoma brucei and the epidemiology of sleeping sickness in the Lambwe Valley, Kenya. Parasitology, 1992, 104, 99-109.

Flockhart H.A., Cibulskis R.E., Karam M. \& Albiez E.J. Onchocerca volvulus - Enzyme polymorphism in relation to the differentiation of forest and savannah strains of this parasite. Transactions of the Royal Society of Tropical Medicine and Hygiene, 1986, 80, 285-292.

Gashumba J.K., BaKer R.D. \& Godfrey D.G. Trypanosoma congolense: the distribution of enzymic variants in East and West Africa. Parasitology, 1988, 96, 475-486.

Gibson W.C., Mehlitz D., Lanham S.M. \& Godfrey D.G. The identification of Trypanosoma brucei gambiense in Liberian pigs and dogs by isoenzymes and by resistance to human plasma. Tropenmedizin und Parasitologie, 1978, 29, 335-345.

Gibson W.C., Marshall T.F.D.C. \& Godfrey D.G. Numerical analysis of enzyme polymorphism: a new approach to the epidemiology and taxonomy of trypanosomes of the subgenus Trypanozoon. Advances in Parasitology, 1980, 18, $175-246$

Godfrey D.G. Types of Trypanosoma congolense. I. Morphological differences. Annals of Tropical Medicine and Parasitology, 1960, 54, 428-438.

Godfrey D.G. Types of Trypanosoma congolense. II. Differences in the course of infection. Annals of Tropical Medicine and Parasitology, 1961, 55, 154-166.

Godfrey D.G. \& KILLICK-Kendrick R. Bovine trypanosomiasis in Nigeria. I. The inoculation of blood into rats as a method of survey in the Donga Valley, Benue province. Annals of Tropical Medicine and Parasitology, 1961, 55, 287-292.

Godfrey D.G., Killick-Kendrick R. \& Ferguson W. Bovine trypanosomiasis in Nigeria. IV. Observations on cattle trekked along a trade-cattle route through areas infested with tsetse fly. Annals of Tropical Medicine and Parasitology, 1965, 59, 255-269.

Godfrey D.G. \& Kilgour V. Enzyme electrophoresis in characterising the causative organism of Gambian trypanosomiasis. Transactions of the Royal Society of Tropical Medicine and Hygiene, 1976, 70, 219-224.

GODFREY D.G. Identification of economically important parasites. Nature, 1978, 273, 600-604.

Godfrey D.G., Baker R.D., Rickman L.R. \& Mehlitz D. The distribution, relationships and identification of enzymic variants within the subgenus Trypanozoon. Advances in Parasitology, 1990, 29, 1-74.

Kilgour V. \& Godfrey D.G. Species-characteristic isoenzymes of two aminotransferases in trypanosomes. Nature, 1973, 244, 364-366.

Kilgour V., Godfrey D.G. \& NA'isa B.K. Isoenzymes of two aminotransferases among Trypanosoma vivax in Nigerian cattle. Annals of Tropical Medicine and Parasitology, 1975, 69, 329-335.

Kilgour V. \& GODFREY D.G. The persistence in the field of two characteristic isoenzyme patterns in Nigerian Trypanosoma vivax. Annals of Tropical Medicine and Parasitology, 1977, 71, 387-389.

LANHAM S.M. \& GODFREY D.G. Isolation of Salivarian trypanosomes from man and other mammals, using DEAE cellulose. Experimental Parasitology, 1970, 28, 521-534.

LeblancQ S.M., Cibulskis R.E. \& Peters W. Leishmania in the Old World. 5. Numerical analysis of isoenzyme data. Transactions of the Royal Society of Tropical Medicine and Hygiene, 1986, 80, 517-524.

LETCH C.A. Host restriction, morphology and isoenzymes among trypanosomes of some freshwater fishes. Parasitology, 1979, 79, 107-117.

McNamara J.J., Mohammed G. \& Gibson W.C. Trypanosoma (Nannomonas) godfreyi sp. nov. from tsetse-flies in The Gambia: biological and biochemical characterization. Parasitology, 1994, 109, 497-509.

Mehlitz D., Zillmann U., Scott C.M. \& Godfrey D.G. Epidemiological studies on the animal reservoir of gambiense sleeping sickness. III. Characterisation of Trypanozoon stocks by isoenzymes and sensitivity to human serum. Tropenmedizin und Parasitologie, 1982, 33, 113-118.

Miles M.A., Toye P.J., Oswald S.C. \& Godfrey D.G. Identification by isoenzyme patterns of two distinct strain-groups of Trypanosoma cruzi, circulating independently in a rural area of Brazil. Transactions of the Royal Society of Tropical Medicine and Hygiene, 1977, 71, 217-225.

SARGEAUNT P.G. \& WiLliams J.E. Electrophoretic isoenzyme patterns of Entamoeba histolytica and Entamoeba coli. Transactions of the Royal Society of Tropical Medicine and Hygiene, 1978, 72, 164-166.

SteVEns J.R. \& Cibulskis R.E. Analysing isoenzyme band patterns using similarity coefficients: a personal computer program, in: Computer Methods and Programs in Biomedicine, 1990, 205-212.

STEVENS J.R. \& GODFREy D.G. Numerical taxonomy of Trypanozoon based on polymorphisms in a reduced range of enzymes. Parasitology, 1992, 104, 75-86.

Stevens J.R., Lanham S.M., Allingham R. \& Gashumba J.K. A simplified method for identifying subspecies and strain groups in Trypanozoon by isoenzymes. Annals of Tropical Medicine and Parasitology, 1992, 86, 9-28.

STEVENS J.R. \& WelbuRn S.C. Genetic processes within an epidemic of sleeping sickness in Uganda. Parasitology Research, 1993, 79, 421-427.

Stevens J.R., Mathieu-Daude F., McNamara J.J., Mizen V.H. \& NzILA A. Mixed populations of Trypanosoma brucei in wild Glossina palpalis palpalis. Tropical Medicine and Parasitology, 1994, 45, 313-318.

Young C.J. \& Godfrey D.G. Enzyme polymorphism and the distribution of Trypanosoma congolense isolates. Annals of Tropical Medicine and Parasitology, 1983, 77, 467-481. 